\title{
Cytoplasmic functions of TDP-43 and FUS and their role in ALS
}

Nicol Birsa ${ }^{1}$, Matthew Peter Bentham ${ }^{1}$ and Pietro Fratta ${ }^{1,2}$

1 Department of Neuromuscular Diseases, UCL Queen Square Institute of Neurology, Queen Square, London, WC1N 3BG, UK

2 MRC Centre for Neuromuscular Disease, Queen Square, London, WC1N 3BG, UK Correspondence: n.birsa@ucl.ac.uk or p.fratta@ucl.ac.uk

\section{Abstract}

TAR DNA-binding protein of $43 \mathrm{kDa}$ (TDP-43) and fused in sarcoma (FUS) are RNA binding proteins (RBPs) primarily located in the nucleus, and involved in numerous aspects of RNA metabolism. Both proteins can be found to be depleted from the nucleus and accumulated in cytoplasmic inclusions in two major neurodegenerative conditions, amyotrophic lateral sclerosis and frontotemporal dementia. Recent evidences suggest that, in addition to their nuclear functions, both TDP-43 and FUS are involved in multiple processes in the cytoplasm, including mRNA stability and transport, translation, the stress response, mitochondrial and autophagy regulation. Here, we review the most recent advances in understanding their functions in the cytoplasm and how these are affected in disease.

\section{Keywords (6)}

TDP-43, FUS, ALS, RNP, translation, stress granules

\section{Abbreviations}

- ALS amyotrophic lateral sclerosis

- FTD frontotemporal dementia

- FUS fused in sarcoma

- LCD low complexity domain

- LLPS liquid-liquid phase separation

- NLS nuclear localisation signal

- RBP RNA binding protein

- RNP ribonucleoprotein

- TDP-43 TAR DNA- binding protein

- UTR untranslated region 


\section{Introduction}

Amyotrophic lateral sclerosis (ALS) is a neurodegenerative disorder, in which the loss of upper and lower motor neurons causes progressive muscle weakness, ultimately leading to death due to respiratory failure. Frontotemporal dementia (FTD) is associated with neurodegeneration of frontal and temporal lobes, leading to progressive behavioural and language changes that result in dementia. The clinical manifestations of ALS and FTD can co-occur, and as the two diseases share several pathological and genetic features, they are now considered part of the same disease spectrum [1].

$5-10 \%$ of ALS cases present with autosomal dominant inheritance. Genomic analysis has allowed the identification of disease-causative mutations, which have subsequently also been found in patients with no familial history. Overall, known pathogenic mutations can be identified in approximately $15 \%$ of ALS cases. A number of these mutations are within genes encoding for RNA binding proteins (RBPs), with the two most frequent ones being TDP-43 and FUS. Moreover, TDP43 is found in cytoplasmic neuronal inclusions in $>97 \%$ of ALS cases and $>40 \%$ of FTD cases [2-4]. These TDP-43 inclusions are now considered a hallmark of ALS pathology, raising an overall strong interest in RNA metabolism in ALS.

TDP-43 and FUS share structural and functional features. Both RBPs comprise RNA recognition motifs (RRMs), a low complexity domain (LCD) and a nuclear localisation signal (NLS). These RBPs localise predominantly to the nucleus, however they can shuttle to and from the cytoplasm [5]. In addition to wellcharacterised nuclear functions such as transcription, mRNA splicing and polyadenylation, miRNA biogenesis, all reviewed elsewhere [6-8], emerging evidence is highlighting roles for TDP-43 and FUS within the cytoplasm. Under physiological conditions, TDP-43 and FUS levels in the cytoplasm are extremely low, making research on these cytoplasmic functions challenging. Conversely, in ALS/FTD, both TDP-43 and FUS are depleted from the nucleus and mislocalise to the cytoplasm at end-stage disease [5]. This has suggested that, in addition to a nuclear loss of function, these proteins may also have a cytoplasmic gain of normal or toxic function, a hypothesis supported by the comparison between FUS knock-out models and mutant FUS ( $\triangle \mathrm{NLS}$ ) knock-in models [9]. In addition, overexpression of wild-type (WT) TDP-43 and FUS, which results in increased cytoplasmic levels of the protein, is associated with neurodegeneration in animal models [10], and pathogenic mutations in FUS 3'UTR, leading to increased protein levels [11], further support this. 
This review aims to summarise the most up-to-date literature regarding the functions of TDP-43 and FUS in the cytoplasm, including mRNA stability and transport, regulation of translation, miRNA processing, the stress response, mitochondrial and autophagy regulation and synaptic function.

\section{Cytoplasmic roles of FUS and TDP-43}

\section{1 mRNA stability}

Gene expression can be regulated post-transcriptionally by tuning mRNA stability, and RBPs binding to mRNAs can regulate this process by favouring or preventing the recruitment of the mRNA decay machinery [12].

TDP-43 binds to the $3^{\prime}$ UTR of numerous mRNAs within cytoplasmic fractions, suggesting a role in mRNA stability and/or transport [13]. TDP-43 was initially shown to bind to the $3^{\prime}$ UTR of NEFL, encoding the neurofilament light chain, and to promote its stability [14]. Similarly, TDP-43 binds to and favours the stability of the transcripts $A d d 2$, coding for the actin binding protein $\beta$-adducin, and HDAC6. TDP-43 knock-down results in decreased HDAC6 protein levels and accumulation of acetyl-tubulin, a major substrate of the protein $[15,16]$. Interestingly, this highlights the fact that TDP-43 promotes the stability and abundance of at least three proteins involved in the regulation of the cytoskeleton and suggests that loss of TDP-43 function can lead to overall cytoskeletal defects, possibly affecting axonal and dendritic maintenance, intracellular transport and ultimately neuronal transmission.

TDP-43, however, has also been reported to reduce transcript stability. Knockdown of the protein results, in fact, in increased stability of the vascular endothelial growth factor a (Vegfa) and progranulin (Grn) mRNAs in motorneuron-like NSC-34 cells [17].

Also FUS can bind $3^{\prime}$ UTRs [18] and Kapeli and colleagues have found that FUS regulates the stability of hundreds of transcripts, promoting the stabilisation of up to 330 mRNAs and destabilising 44 transcripts in human neural progenitor cells [19]. In addition to this, recent work from the Sobue lab has elegantly dissected the mechanisms underlying FUS-dependent stability of the glutamate AMPA receptor subunit Gria1 (GluA1) and the synaptic Ras-GTPase activating protein $\alpha 2$, synGAP $\alpha 2$. Down-regulation of FUS in hippocampal neurons is associated with shortening of Gria1 poly-adenylation tail. The authors have shown FUS to be normally present in a complex with three $3^{\prime}$-end processing factors (CPSF6, PAN2, PABPC1); while FUS normally sequesters PAN2, and prevents it from deadenylating Gria1, loss of FUS results in the deadenylation of the transcript, leading to decreased stability and reduced protein levels [20]. 
SynGAP $\alpha 2$ regulation is, instead, mediated by FUS binding to the transcript long 3'UTR and promoting its interaction with ELAVL4/HuD. Loss of FUS leads to impaired association of ELAVL4/HuD with the transcript and increased interaction with ELAVL1/HuR. This results in decreased transcript stability and a consequent reduction in synGAP 2 protein, which in turn leads to the internalisation of the post-synaptic protein PSD-95 [21].

In addition to regulating stability in a transcript-specific fashion, FUS mutants have been shown to induce the upregulation of mRNA nonsense-mediated decay (NMD) machinery, resulting in a decrease of transcript stability and consequent reduction in translation [22].

\section{2 mRNA transport}

Neurons are highly polarised, architecturally complex cells. Synaptic terminals are often located at a considerable distance from the cell body, therefore mRNA transport and local translation are critical to maintain and remodel the synaptic proteome in order to sustain efficient neuronal function. mRNAs are transported in the form of ribonucleoprotein (RNP) complexes or RNA granules. These are constituted by RBPs that can bind the $5^{\prime}$ UTR, $3^{\prime}$ UTR, or the coding region of a transcript and can coordinate its stability, transport and/or translation. Components of these granules include Staufen proteins, FMRP, hnRNPA2, CPEB, SMN, ZBP1 and Pura [23].

TDP-43 co-purifies with various proteins involved in mRNA transport, such as Staufen, FMRP and SMN [24, 25], it is transported along axonal and dendritic processes [25-27], and has been detected both at pre- and post-synaptic terminals $[28,29]$. TDP-43 transport is bidirectional and depends on the microtubule cytoskeleton. The majority of TDP-43 granules are co-labelled by RNA dyes, indicating that these granules contain RNA [30]. Moreover, TDP-43 association with Nefl results in increased anterograde movement of the transcript [27].

Compared to WT TDP-43, its mutants (M337V and A315T) are not as efficiently transported, with increased pausing and a preference for retrograde versus anterograde transport both in primary cortical neurons and in vivo in Drosophila motor neurons $[27,30]$. This results in an increased localisation in regions proximal to the cell body and depletion from the neurite tips [27]. The characteristics of TDP-43 granules have been suggested to differ depending on their localisation along the axon. In the proximal part of the axon, TDP-43 positive granules are more stationary and viscous compared to those located in the mid axon. Interestingly, granules formed by TDP-43 mutants (M337V and 
G298S), even when located in the mid axon, were characterised by a viscosity 20 times higher than those formed by the WT protein [30], which may contribute to altered transport and mRNA delivery.

FUS also localises to axonal and dendritic terminals [31-33] and biochemical assays have shown it to co-precipitate with the microtubule motor KIF5 in mouse brain [34], suggesting that the protein is actively transported in neurons. FUS also binds the actin motor myosin $\mathrm{Va}$, which mediates the translocation of FUS into dendritic spines upon DHPG-dependent mGluR activation [35]. In addition, DHPG induces the transport of Nd1-L mRNA into dendrites; this is impaired in FUS null mice, supporting a role for FUS in Nd1-L transport [36].

\subsection{Translation}

RBPs can modulate protein translation, both globally and in a transcript-specific fashion. By regulating 4E binding proteins (4E-BPs), RBPs can impair the association of eIF4E with the translation initiation complex. Likewise, regulation of eIF $2 \alpha$ phosphorylation can affect the ability of the protein to deliver the initiator Met-tRNA to the ribosome, hence affecting the initiation of translation [37]. RBPs can also alter the synthesis of specific transcripts, for example by regulating the availability of specific mRNAs at sites of translation, affecting their association with the actively translating polysomal fractions, or promoting miRNA dependent regulation of protein synthesis [38].

Regulation of translation by TDP-43 and FUS has not been widely investigated, however, there is growing evidence to show that these proteins interact with ribosomal subunits and translation regulation factors [22, 24, 39]. Moreover, in fractionation studies, TDP-43 and FUS co-migrate with both actively translating polyribosomal fractions as well as non-translating RNP fractions comprising monosomes, ribosomal subunits and RNP complexes [36, 40]. This suggests that TDP-43 and FUS may have roles in regulating several aspects of protein translation.

TDP-43 can repress translation in vitro [29], and overexpression of cytoplasmic $\triangle$ NLS TDP-43 in SH-SY5Y cells leads to decreased global translation rates. This is associated with a decrease in the phosphorylation of eIF4E and an increase in the expression of the translation repressor 4E-BP, supporting a role for TDP-43 to limit protein synthesis rates [41].

In addition to regulating protein synthesis globally, TDP-43 can specifically repress the translation of several transcripts. Binding of TDP-43 to Rac1 mRNA promotes its association with a FMRP/CYFIP1 complex, leading to its depletion from the polysomal fractions and a consequent reduction in protein levels [42, 
43]. Similar to Rac1, also Map1b (Futsch) and Gria1 (GluA1) mRNAs bind TDP-43 and are both enriched in the polysomal fractions upon TDP-43 knock-down, suggesting a similar regulation mechanism [42]. The role of FMRP in this TDP-43dependent regulation is, however, unclear. On one hand, FMRP has been suggested to mediate the repression of TDP-43 targets. In fact, similar to TDP-43 knock-down, FMRP down-regulation results in increased translation of Map1b and Gria1 [42]. On the other hand, overexpression of FMRP (dFMR1) has been suggested to mitigate the effect of TDP-43 by remodelling TDP-43 granules and rescuing the translation of MAP1B [40].

However, TDP-43 has not just been associated with protein repression. Recent findings, in fact, have highlighted a role for TDP-43 as a translational enhancer. Ribosome profiling experiments by Neelagandan and colleagues have shown that TDP-43 promotes the ribosomal association of Camta1, Mig12, Dennd4a mRNAs without affecting their expression level. Both WT and mutant TDP-43 can bind Camta1 and Mig12 5'UTR and promote their translation. Instead, TDP-43dependent Dennd4a regulation is only mediated by mutant TDP-43, which binds the 3' UTR region of the transcript and promotes its translation [44]. Enhanced translation in a mutant TDP-43 mouse model (A315T) has also been reported for $C c / 4$ and $D d x 58$, however it is unclear whether this is due to differential transcript expression or increased synthesis [45].

Fewer studies have investigated the role of FUS in the regulation of translation. In a recent paper, Lopez-Erauskin and colleagues have shown that, in a transgenic mouse, expression of human mutant FUS $(\mathrm{R} 521 \mathrm{H})$, but not WT, impairs global translation in motor neuron axons. This is associated with an increase in eIF $2 \alpha$ phosphorylation, in agreement with reduced protein synthesis [46]. Similarly, various FUS mutants (R522G, R524S, R495X, FUS-501) were shown to impair protein synthesis in the growth cones of Xenopus retinal ganglion cells [47].

FUS has, nevertheless, also been shown to positively regulate translation. At APC-containing RNPs in fibroblast protrusions, FUS promotes translation, but not localisation, of mRNAs that have been previously found to be associated with APC granules (Pkp4, Kank2, Ddr2). Cytoplasmic aggregates caused by overexpression of FUS mutants promote the recruitment of APC and other APC-containing RNPS proteins and mRNAs. These are not, however, sites of translational repression, rather, APC-related mRNAs are actively translated in these granules [48].

Although initial evidence supports a role for both FUS and TDP-43 in translation, the molecular mechanisms by which they contribute to the regulation of protein synthesis are not fully understood and additional work will be needed to further dissect this process. 


\section{4 miRNA processing}

microRNAs (miRNA) are short RNAs that play an important role in regulating mRNA stability and translation. The mature miRNAs are 21-23 nucleotides long and are processed from an initial longer RNA molecule (pri-miRNA) by two cleavage steps: the first is dependent on Drosha in the nucleus and generates pre-miRNAs; the second occurs in the cytoplasm through DICER and results in the mature miRNA. miRNAs are important for the survival of motor neurons, and dysregulation of numerous miRNAs, as well as a general reduction of their maturation, have been associated with ALS [49, 50], as recently reviewed [51, 52]. TDP-43 and FUS have been shown to be involved in miRNA maturation at numerous steps. Both RBPs can bind to specific immature miRNAs and both RBPs can also directly bind to Drosha and/or DICER, and their absence can impact on the maturations of selected miRNAs [53-56].

The finding that loss of TDP-43 induces a neurite outgrowth phenotype, which can be mostly rescued by the correction of specific miRNAs, along with the recent finding that miRNAs can be processed by DICER in neurites and play an important role in local neurite protein translation $[53,57]$ are intriguing. Whether these processes are impaired in TDP-43 and FUS-ALS is yet to be explored.

\subsection{Stress response and LLPS}

Another cytoplasmic process influenced by TDP-43 and FUS is the formation of cytoplasmic stress granules (SGs). These membrane-less organelles have been demonstrated to assemble in response to environmental stressors, such as oxidative stress, heat shock and osmotic stress, and subsequently disassemble upon stress cessation [58]. These dynamic structures undergo fusion, coalescence, interaction with other membrane-less organelles such as P bodies, and disassembly [59-61]. SG formation is hypothesised to be driven by liquidliquid phase separation (LLPS). A number of the RBPs mutated in ALS are known to undergo phase separation in vitro (hnRNPA1, TIA1), driven by their low complexity domains (LCDs), and to localise to SGs $[62,63]$.

In vitro, both WT FUS and TDP-43 can undergo LLPS, with ALS-causing mutations increasing their propensity to do so $[47,64,65]$. Further, endogenous TDP-43 and FUS proteins localise to SGs after treatment with the oxidative stressor sodium arsenite [66-68]. Although some studies have indicated that WT FUS does not enter SGs following oxidative stress $[69,70]$, more sensitive techniques, such as mass spectrometry and proximity labelling have confirmed its presence [66, 67]. Additionally, FUS mutants have been shown to localise to a larger extent to 
these structures [71], even in model systems where the protein is expressed at endogenous levels, such as knock-in mouse models, patient-derived fibroblasts and iPSC cells [72-74]. The amount of FUS colocalisation with SGs correlates with its degree of cytoplasmic mislocalisation [75]. Other factors can impact on the cytoplasmic LLPS and SG inclusion of FUS, such as transportin 1 (TNPO1). TNPO1 not only mediates FUS nuclear import, but it can also act as cytosolic chaperone. In fact, by binding WT, but not NLS mutant FUS, TNPO1 can regulate the protein LLPS dynamics and its inclusion in SGs [76, 77].

While endogenous WT FUS has not been shown to impact on SG dynamics, knock-down of TDP-43, causes both delayed assembly/coalescence and accelerated SG disassembly of SGs, through altered expression of key SG proteins, such as Ras GTPase-activating protein-binding protein 1 (G3BP1) and TIA1 [61, 78, 79].

Instead, mutations in both FUS and TDP-43 alter many aspects of SGs, including SG size [80, 81], abundance [73, 81, 82], assembly [81] and disassembly [73, 81, 83]. Further, ALS-causing mutations in both FUS and TDP-43 alter the biophysical properties, such as viscosity, of intracellular RNP granules [30]. Of note, a recent study utilised background-deflection Brillouin microscopy to show that mutant FUS expression can alter both the viscosity and stiffness of SGs [84]. As SG proteins have been detected within ALS TDP-43- and FUS-positive inclusions $[75,85,86]$, it has been hypothesised that SGs may become, or nucleate these inclusions [87]. It has been demonstrated in vitro that insoluble fibrils can form within phase separated compartments $[47,63]$ and, using a chronic oxidative stress model in cells, insoluble ubiquitin-positive TDP-43 aggregates have been shown to persist following stress cessation [88]. Recently, an optogenetic method of inducing SG-like cytoplasmic granules identified a timedependent conversion of SGs to ALS-like inclusions with phosphorylated TDP-43 and ubiquitin, supporting that RNP granules may be the precursors of the inclusions observed in disease [89].

Recent work has also pointed to the fact that TDP-43 may form granules independently of stress, although the stress response does appear to be important for the transition of these granules to more stable aggregates [90].

Intriguingly, TDP-43 has also been demonstrated to form 'myo-granules' in developing and regenerating skeletal-muscle tissue, which have been demonstrated to seed TDP-43 fibrils in vitro [91]. This highlights another system, alongside SGs, in which TDP-43 foci, occurring as part of a physiological cellular response, can lead to the formation of protein aggregates, which are considered hallmarks of disease. 
How the transition from liquid granules into more persistent aggregates occurs in patients yet needs to be elucidated, but the presence of RNA has been shown to potentially play a role. TDP-43 and FUS aggregation is facilitated by the loss of their RNA binding capacity and, conversely, an increase in RNA can limit aggregate formation. In agreement with this, RNA appears to be depleted from TDP-43 inclusions in post mortem patient brains, supporting a role for RNA in this process in human disease $[92,93]$.

In summary, TDP-43 and FUS both participate in, and can impact on the stress granule response. Further, current data supports a link between SGs and the hallmark disease inclusions, and intriguingly RNA is potentially an important factor in the transition between these physiological granules and the disease inclusions.

\subsection{Mitochondria}

Increasing evidence is supporting a role for mitochondrial dysfunction in the pathogenesis of ALS, however, it is unclear whether this is due to a direct role of ALS-related proteins in mitochondrial functionality, transport and/or dynamics or it is a consequence of neuronal degeneration, inflammation or the stress response. TDP-43 and FUS localise to mitochondria in neurons [94, 95]. Whilst WT TDP-43 and FUS show limited localisation to these organelles, likely as a consequence of the very low levels present in the cytoplasm, ALS-linked mutants, show increased levels at the mitochondrion [94, 95]. The increased cytoplasmic presence of mutant TDP-43 is likely to lead to its mitochondrial enrichment, nevertheless, recombinant TDP-43 mutants (G298S, A315T and A382T) are imported more efficiently than the WT protein into purified brain mitochondria [94], suggesting ALS-associated TDP-43 can intrinsically accumulate in these organelles. Once inside the mitochondrion, TDP-43 localises to the inner mitochondrial membrane where it binds to and prevents the translation of several mRNAs of mitochondrially-encoded subunits of the electron transport chain (ETC) complexes, resulting in mitochondrial fragmentation, decreased membrane potential, reduced oxygen consumption and ATP production [94, 96]. However, other reports have failed to find mitochondrial dysfunction in TDP-ALS models or upon changes in TDP-43 expression levels [97].

Similar to TDP-43, FUS localises to mitochondria both in overexpression systems and in post mortem tissue [95, 98]. FUS localisation to mitochondria is dependent on HSP60 expression [98]. At the mitochondrion FUS has been suggested to directly affect mitochondrial functionality; by binding the beta subunit of the ATP synthase, it was shown to impact on the availability of beta subunits ready to be assembled into the mature ATP synthase complex, causing a decrease in the ATP 
production rate and promoting the mitochondrial unfolded protein response (mtURP)[95].

To date, FUS has not been reported to regulate the stability or translation of mitochondrially encoded transcripts, however, RNAseq analysis of aged spinal cords of a FUS mutant knock-in mouse (delta14 FUS) has shown a decrease in the expression of mitochondrial transcripts [72]. In addition, overexpression of a FUS mutant (R495X) in mouse ES-derived neurons, leads to decreased expression of mitochondrially-associated proteins such as KIF5B, Dnm1l, Csde1 [99]. These proteins are not uniquely associated with mitochondria and whether mutations in FUS can directly affect mitochondrial function needs to be further investigated.

TDP-43 and FUS have also been shown to modulate other aspects of mitochondrial biology. For example, TDP-43 interacts with proteins involved in mitophagy such as prohibitin, PHB2 [100]. Moreover, in overexpression systems, both TDP-43 and FUS have been shown to disrupt the ER-mitochondria contact sites by impairing the VAPB/PTPIP51 interaction through the activation of GSK3beta. This results in increased cytosolic calcium levels and impaired in ATP production [101, 102].

Overall there is a growing body of evidence indicating a role for both RBPs in mitochondrial function. Nevertheless, more work will be required to better understand how they impair mitochondrial functionality, as experiments reported so far have predominantly been performed in overexpression systems.

\subsection{Autophagy}

Autophagy is a homeostatic mechanism by which intracellular components are degraded and subsequently recycled. This process is tightly regulated by a network of proteins, including the autophagy-related (ATG) proteins, as well as a number of proteins mutated in ALS, such as VCP, optineurin, SQSTM1/p62 and ubiquilin-2 [103].

TDP-43 has also been indicated to regulate autophagy. Knock-down studies demonstrate that TDP-43 binds to Atg7 transcripts, resulting in decreased mRNA stability and subsequent impairment of autophagy [104]. Moreover, TDP-43 knock-down has been demonstrated to down-regulate $A T G 4 B$ transcript levels, possibly through cryptic exon inclusion, leading to alterations in the autophagy process [105]. TDP-43 down-regulation also strongly induces a nuclear translocation of TFEB, the master regulator of autophagy, altering ATG expression and impairing the fusion of autophagosomes with lysosomes [106]. 
Conversely, overexpression of both WT and mutant TDP-43 (A315T) in SH-SY5Y cells increases autophagic activity, as measured by expression of macroautophagic markers. Inhibition of autophagy resulted in increased cell death, particularly in TDP-43 (A315T) cells, indicating that autophagy is cytoprotective in these mutants [107].

While the impact of FUS on autophagy is comparatively understudied, mutant FUS has been demonstrated to perturb this process. Overexpression of FUS mutants (P525L and R522G), but not WT FUS, inhibits autophagy by preventing the formation of both omegasomes (autophagosome precursors) and autophagosomes; an effect rescued by overexpression of Rab1 [108]. Another study demonstrated, using a fluorescence reporter assay, that overexpression of WT or mutant (R521C) FUS does not affect the autophagic flux, but that autophagy is important for the removal of FUS-positive SGs [109].

Overall, there are initial evidences highlighting roles for TDP-43 and FUS in the regulation of autophagy, supporting the idea that this process, which, among others, is important for the clearance of cytoplasmic aggregates, may be impaired in TDP-43/FUS-ALS.

\subsection{Neuronal function and synaptic roles}

Local translation has been shown to be required for most aspects of neuronal life: from neurite development and stabilisation or retraction to synapse formation, maturation and plasticity [110,111].

RBPs such as TDP-43 and FUS have roles in various aspects of RNA metabolism and hence can affect neuronal activity in multiple ways: by modulating the expression and splicing of certain transcripts, or by targeting the transport, stability and/or translation of specific mRNAs. Gene ontology analysis of TDP-43 and FUS targets has revealed an enrichment in synaptic and neural development categories, with targets ranging from ionotropic channels to transynaptic proteins such as neurexins and neuroligins [112-114], suggesting that alterations in TDP43 and FUS levels and/or localisation could alter the composition of the synaptic environment.

Both reduction and increase in TDP-43 and FUS expression levels are associated with impaired neurite morphology. However, there is little consensus on how the morphology of the dendritic and axonal networks is affected by TDP-43, with reports indicating that alterations in TDP-43 levels can both decrease neurite length and complexity $[25,115]$, increase them [116], or alter spine formation but not the dendritic network [43]. 
As for FUS, reports have been more consistent, finding that overexpression in cultured neurons or in vivo of WT or mutant FUS results in a decrease in dendritic complexity [117-119]; however Herzog and colleagues have failed to replicate this by WT FUS overexpression in cultured neurons [115].

Both TDP-43 and FUS have been shown to localise at synaptic terminals. The presence of TDP-43 in the dendritic compartment can be variable, in fact only $50 \%$ of cultured hippocampal neurons have TDP-43 positive granules in their dendritic arbour [26], where it colocalises with SYTO14 positive RNA-containing particles [29] and the RBP TIA1 [26]. Neuronal activity elicited by $\mathrm{KCl}$ can favour this translocation, resulting in higher TDP-43 levels in dendrites and an increased colocalisation of TDP-43 with the postsynaptic marker PSD-95 [29, 120]. Compared to WT TDP-43, ALS-associated mutants (A314T and Q343R) form larger granules in the cytoplasm and do not relocate to the dendritic arbour upon stimulation of neuronal activity to the same extent as their WT counterpart. Interestingly, the increase in granule size was not due to a higher cytoplasmic content of the mutants, as the cytoplasmic K82-84A TDP-43, carrying a double mutation in the NLS, presented similar granule size to WT [26].

Likewise, stimulation with BDNF triggers a $78 \%$ increase in TDP-43 localisation in motor neuron axons [25], where it colocalises with several other RBPs such as FMRP, SMN, IMP1, HuD and Staufen [25, 27], suggesting that TDP-43 is, at least in part, a component of more heterogeneous RNP granules.

As previously described, Nefl and Map1b (Futsch) mRNAs have been found in TDP-43 axonal granules [27, 121, 122]. While the cellular consequences of an impaired axonal transport of Nefl due to mutant TDP-43 have not been explored, a decrease in MAP1B expression at the NMJ and consequent disruption in NMJ morphology, have been associated with TDP-43 overexpression in Drosophila $[121,122]$. This was shown to be due to a depletion of Map1b mRNA from the actively translating polysomal fraction caused by the overexpression of both WT or mutant TDP-43 [121]. Similarly, mutant TDP-43 (G298S) has been shown to bind to HSPA8 (HsC70-4) mRNA, leading to its depletion from polysomes and a reduction in translation at the NMJ. HSPA8 is a critical chaperone involved in synaptic vesicle recycling, and mutant TDP-43-dependent down-regulation of the protein is associated with disruption in synaptic vesicle endocytosis in Drosophila [123].

The first evidence showing FUS to be present at the synapse came from a proteomic screen for interactors of the NMDA receptor [124]. Since, FUS has been shown to localise to the dendritic as well as the axonal compartment [31, $32,36,125]$. The cytoplasmic and dendritic levels of FUS in both human post- 
mortem brains and murine brains varies depending on the different regions, with the cerebellum, midbrain, pons, medulla oblongata and spinal cord having higher levels compared to the neocortex [125]. Similar to TDP-43, FUS localisation to the dendrites is also regulated by neuronal activity. mGluR activation through DHPG promotes FUS translocation to dendrites and spines (with 5 times increased immunoreactivity) [31]. In agreement with this, FUS (and various hnRNPs) levels increase in purified post synaptic density (PDS) preparations following long term potentiation [33]. Interestingly, Fujii and colleagues have shown that FUS localisation to dendrites and spines occurs mainly in mature hippocampal neurons (DIV 23) [31], further supporting the idea that neuronal activity is required for the re-localisation of cytoplasmic FUS.

As described in section 2.1, FUS regulates the stability of the AMPA receptor subunit Gria1 (GluA1) mRNA and therefore its expression. Loss of FUS in the hippocampus results in a reduction in spontaneous excitatory activity and a decrease in the number of mature spines, similar to the effect of Gria1 knockdown [20]. Furthermore, by regulating the stability of synGAP $\alpha 2$, FUS determines the synaptic amount of synGAP 22 protein, which in turn modulates PSD-95 localisation to dendritic spines and spine maturation [21]. In addition to this, FUS binds and promotes the transport of Nd1-L mRNA, following neuronal activity. $\mathrm{Nd1-L}$ is an actin stabilising protein that promotes spine stability following cytochalasin B treatment [36]. FUS can therefore regulate various aspects of spine maturation and stability, from tuning the levels of AMPA receptors, to regulating the expression of synGAP $\alpha 2$ and consequently PSD-95, but can also contribute to the stabilisation of the actin cytoskeleton via Nd1-L. Notably WT FUS (but not mutant) is translated at the post-synaptic density following DHPG stimulation [117]. This suggests that a feed forward mechanism may be in place, whereby FUS could regulate and/or maintain synaptic homeostasis.

Although FUS has been shown to be present at the pre-synapse of hippocampal neurons by super-resolution microscopy, little is known about its role in this compartment, in particular at the neuromuscular junction (NMJ). Initial studies in Drosophila indicate that overexpression of WT or mutant FUS leads to NMJ disruption, with a decrease in both pre-synaptic and post-synaptic proteins (bruchpilot and DIg), synaptic projection degeneration, reduced evoked excitatory endplate potential, increased calcium transients and synaptic fatigue $[118,126]$. This suggests that FUS may have direct or indirect roles in the regulation of presynaptic activity, however further studies will be needed to further dissect the mechanisms involved in FUS-dependent synaptic regulation, and in particular its role at the NMJ. 


\section{Conclusions}

Despite their low levels in the cytoplasm, endogenous WT TDP-43 and FUS have been shown to be involved in several functions outside the nucleus (Figure 1). ALS-associated TDP-43 and FUS mutants are characterised by various degrees of cytoplasmic mislocalisation. On one hand this is compatible with a nuclear loss of function, exhaustively reviewed elsewhere [6-8]; however, new evidence also supports the association of ALS-linked TDP-43 and FUS mutants with a gain of cytoplasmic function.

TDP-43 and FUS undergo LLPS, which promotes the formation of membrane-less structures enclosing other RBPs and mRNAs. Mutations in TDP-43 and FUS can alter LLPS dynamics, leading to more viscous and less mobile particles [30, 127]. This may prevent TDP-43 and FUS, and their target transcripts, from being readily available for a multitude of cytoplasmic processes, and also lead to the sequestration and confinement of various other RBPs, such as SMN [128], causing a more generalised impairment in RNA metabolism. Moreover, the inclusion of TDP-43 and FUS into cytoplasmic aggregates can also induce and/or exacerbate the nuclear depletion of these proteins, leading to dramatic molecular consequences that are likely to play a role in neuronal death at the late stages of disease. Interestingly, the consequences of nuclear depletion of TDP-43 may play a more significant role compared to those of FUS. In fact, while loss of TDP-43 has dramatic effects on mature motor neurons $[129,130]$, the lack of FUS results in relevant, but less extensive impairments [131]. These are likely to play an important, but complementary role to FUS cytoplasmic gain of function in disease pathogenesis.

Overall, there is a growing body of evidence highlighting various functions of TDP-43 and FUS in the cytoplasm. Critically, many experiments have involved overexpression systems or transgenic models and, given the tight regulation of TDP-43 and FUS expression, it will be important to confirm and strengthen these findings in endogenous models. Moreover, a better understanding of the molecular mechanisms underling these processes will be crucial to gain insight into how these pathways are altered in disease.

\section{Acknowledgements}

We thank Francesca Mattedi and Oscar Wilkins for critically reading this review and Agnieszka Ule for the continuous discussion. PF is funded by an MRC/MNDA 
LEW Fellowship, the NIHR- UCLH Biomedical Research Centre and the Rosetrees Foundation. MB is supported by a Wolfson PhD fellowship.

\section{Declaration of interests}

None declared

\section{References}

[1] F.B. Gao, S. Almeida, R. Lopez-Gonzalez, Dysregulated molecular pathways in amyotrophic lateral sclerosis-frontotemporal dementia spectrum disorder, EMBO J 36(20) (2017) 2931-2950.

[2] E.L. Scotter, H.J. Chen, C.E. Shaw, TDP-43 Proteinopathy and ALS: Insights into Disease Mechanisms and Therapeutic Targets, Neurotherapeutics 12(2) (2015) 35263.

[3] J. Brettschneider, K. Del Tredici, J.B. Toledo, J.L. Robinson, D.J. Irwin, M. Grossman, E. Suh, V.M. Van Deerlin, E.M. Wood, Y. Baek, L. Kwong, E.B. Lee, L. Elman, L. McCluskey, L. Fang, S. Feldengut, A.C. Ludolph, V.M. Lee, H. Braak, J.Q. Trojanowski, Stages of pTDP-43 pathology in amyotrophic lateral sclerosis, Ann Neurol 74(1) (2013) 20-38.

[4] T. Lashley, J.D. Rohrer, S. Mead, T. Revesz, Review: an update on clinical, genetic and pathological aspects of frontotemporal lobar degenerations, Neuropathol Appl Neurobiol 41(7) (2015) 858-81.

[5] K. Kapeli, F.J. Martinez, G.W. Yeo, Genetic mutations in RNA-binding proteins and their roles in ALS, Hum Genet 136(9) (2017) 1193-1214.

[6] H. Ederle, D. Dormann, TDP-43 and FUS en route from the nucleus to the cytoplasm, FEBS Lett 591(11) (2017) 1489-1507.

[7] Y. Shang, E.J. Huang, Mechanisms of FUS mutations in familial amyotrophic lateral sclerosis, Brain Res 1647 (2016) 65-78.

[8] A. Ratti, E. Buratti, Physiological functions and pathobiology of TDP-43 and FUS/TLS proteins, J Neurochem 138 Suppl 1 (2016) 95-111.

[9] J. Scekic-Zahirovic, O. Sendscheid, H. El Oussini, M. Jambeau, Y. Sun, S. Mersmann, M. Wagner, S. Dieterle, J. Sinniger, S. Dirrig-Grosch, K. Drenner, M.C. Birling, J. Qiu, Y. Zhou, H. Li, X.D. Fu, C. Rouaux, T. Shelkovnikova, A. Witting, A.C. Ludolph, F. Kiefer, E. Storkebaum, C. Lagier-Tourenne, L. Dupuis, Toxic gain of 
function from mutant FUS protein is crucial to trigger cell autonomous motor neuron loss, EMBO J 35(10) (2016) 1077-97.

[10] F. De Giorgio, C. Maduro, E.M.C. Fisher, A. Acevedo-Arozena, Transgenic and physiological mouse models give insights into different aspects of amyotrophic lateral sclerosis, Dis Model Mech 12(1) (2019).

[11] M. Sabatelli, A. Moncada, A. Conte, S. Lattante, G. Marangi, M. Luigetti, M. Lucchini, M. Mirabella, A. Romano, A. Del Grande, G. Bisogni, P.N. Doronzio, P.M. Rossini, M. Zollino, Mutations in the 3' untranslated region of FUS causing FUS overexpression are associated with amyotrophic lateral sclerosis, Hum Mol Genet $22(23)(2013) 4748-55$.

[12] X. Wu, G. Brewer, The regulation of mRNA stability in mammalian cells: 2.0, Gene 500(1) (2012) 10-21.

[13] J.R. Tollervey, T. Curk, B. Rogelj, M. Briese, M. Cereda, M. Kayikci, J. König, T. Hortobágyi, A.L. Nishimura, V. Župunski, R. Patani, S. Chandran, G. Rot, B. Zupan, C.E. Shaw, J. Ule, Characterizing the RNA targets and position-dependent splicing regulation by TDP-43, Nature Neuroscience 14 (2011) 452-458.

[14] M.J. Strong, K. Volkening, R. Hammond, W. Yang, W. Strong, C. Leystra-Lantz, C. Shoesmith, TDP43 is a human low molecular weight neurofilament (hNFL) mRNAbinding protein, Molecular and Cellular Neuroscience 35 (2007) 320-327. [15] F.C. Fiesel, A. Voigt, S.S. Weber, C. Van Den Haute, A. Waldenmaier, K. Görner, M. Walter, A.L. Marlene, J.V. Kern, T.M. Rasse, T. Schmidt, W. Springer, R. Kirchner, M. Bonin, M. Neumann, V. Baekelandt, M. Alunni-Fabbroni, J.B. Schulz, P.J. Kahle, Knockdown of transactive response DNA-binding protein (TDP-43) downregulates histone deacetylase 6, EMBO Journal 29 (2010) 209-221.

[16] L. Costessi, F. Porro, A. laconcig, A.F. Muro, TDP-43 regulates $\beta$-adducin (Add2) transcript stability, RNA Biology 11 (2014) 1280-1290.

[17] C. Colombrita, E. Onesto, F. Megiorni, A. Pizzuti, F.E. Baralle, E. Buratti, V. Silani, A. Ratti, TDP-43 and FUS RNA-binding proteins bind distinct sets of cytoplasmic messenger RNAs and differently regulate their post-transcriptional fate in motoneuron-like cells, Journal of Biological Chemistry 287 (2012) 15635-15647. [18] B. Rogelj, L.E. Easton, G.K. Bogu, L.W. Stanton, G. Rot, T. Curk, B. Zupan, Y. Sugimoto, M. Modic, N. Haberman, J. Tollervey, R. Fujii, T. Takumi, C.E. Shaw, J. Ule, 
Widespread binding of FUS along nascent RNA regulates alternative splicing in the brain, Sci Rep 2 (2012) 603.

[19] K. Kapeli, G.A. Pratt, A.Q. Vu, K.R. Hutt, F.J. Martinez, B. Sundararaman, R. Batra, P. Freese, N.J. Lambert, S.C. Huelga, S.J. Chun, T.Y. Liang, J. Chang, J.P. Donohue, L. Shiue, J. Zhang, H. Zhu, F. Cambi, E. Kasarskis, S. Hoon, M. Ares, C.B. Burge, J. Ravits, F. Rigo, G.W. Yeo, Distinct and shared functions of ALS-associated proteins TDP-43, FUS and TAF15 revealed by multisystem analyses, Nature Communications 7 (2016) $1-14$.

[20] T. Udagawa, Y. Fujioka, M. Tanaka, D. Honda, S. Yokoi, Y. Riku, D. Ibi, T. Nagai, K. Yamada, H. Watanabe, M. Katsuno, T. Inada, K. Ohno, M. Sokabe, H. Okado, S. Ishigaki, G. Sobue, FUS regulates AMPA receptor function and FTLD/ALS-associated behaviour via GluA1 mRNA stabilization, Nature Communications 6 (2015) 7098. [21] S. Yokoi, T. Udagawa, Y. Fujioka, D. Honda, H. Okado, H. Watanabe, M. Katsuno, S. Ishigaki, G. Sobue, 3' UTR Length-Dependent Control of SynGAP Isoform $\alpha 2$ mRNA by FUS and ELAV-like Proteins Promotes Dendritic Spine Maturation and Cognitive Function, Cell Reports 20 (2017) 3071-3084.

[22] M. Kamelgarn, J. Chen, L. Kuang, H. Jin, E.J. Kasarskis, H. Zhu, ALS mutations of FUS suppress protein translation and disrupt the regulation of nonsense-mediated decay, Proc Natl Acad Sci U S A 115(51) (2018) E11904-E11913.

[23] M.A. Kiebler, G.J. Bassell, Neuronal RNA granules: movers and makers, Neuron 51(6) (2006) 685-90.

[24] B.D. Freibaum, R.K. Chitta, A.A. High, J.P. Taylor, Global analysis of TDP-43 interacting proteins reveals strong association with RNA splicing and translation machinery, Journal of Proteome Research 9 (2010) 1104-1120.

[25] C. Fallini, G.J. Bassell, W. Rossoll, The ALS disease protein TDP-43 is actively transported in motor neuron axons and regulates axon outgrowth, Human Molecular Genetics 21 (2012) 3703-3718.

[26] L. Liu-Yesucevitz, A.Y. Lin, A. Ebata, J.Y. Boon, W. Reid, Y.-F. Xu, K. Kobrin, G.J. Murphy, L. Petrucelli, B. Wolozin, ALS-Linked Mutations Enlarge TDP-43-Enriched Neuronal RNA Granules in the Dendritic Arbor, Journal of Neuroscience 34 (2014) 4167-4174. 
[27] N.H. Alami, R.B. Smith, M.a. Carrasco, L.a. Williams, C.S. Winborn, S.S.W. Han, E.

Kiskinis, B. Winborn, B.D. Freibaum, A. Kanagaraj, A.J. Clare, N.M. Badders, B. Bilican, E. Chaum, S. Chandran, C.E. Shaw, K.C. Eggan, T. Maniatis, J.P. Taylor, Axonal Transport of TDP-43 mRNA Granules Is Impaired by ALS-Causing Mutations, Neuron 81 (2014) 536-543.

[28] R.K. Narayanan, M. Mangelsdorf, A. Panwar, T.J. Butler, P.G. Noakes, R.H. Wallace, Identification of RNA bound to the TDP-43 ribonucleoprotein complex in the adult mouse brain, Amyotroph Lateral Scler Frontotemporal Degener 14(4) (2013) 252-60.

[29] I.F. Wang, L.S. Wu, H.Y. Chang, C.K.J. Shen, TDP-43, the signature protein of FTLD-U, is a neuronal activity-responsive factor, Journal of Neurochemistry 105 (2008) 797-806.

[30] P.P. Gopal, J.J. Nirschl, E. Klinman, E.L. Holzbaur, Amyotrophic lateral sclerosislinked mutations increase the viscosity of liquid-like TDP-43 RNP granules in neurons, Proc Natl Acad Sci U S A 114(12) (2017) E2466-E2475.

[31] R. Fujii, S. Okabe, T. Urushido, K. Inoue, A. Yoshimura, T. Tachibana, T. Nishikawa, G.G. Hicks, T. Takumi, The RNA binding protein TLS is translocated to dendritic spines by mGluR5 activation and regulates spine morphology, Current Biology 15 (2005) 587-593.

[32] M. Schoen, J.M. Reichel, M. Demestre, S. Putz, D. Deshpande, C. Proepper, S. Liebau, M.J. Schmeisser, A.C. Ludolph, J. Michaelis, T.M. Boeckers, Super-Resolution Microscopy Reveals Presynaptic Localization of the ALS/FTD Related Protein FUS in Hippocampal Neurons, Frontiers in Cellular Neuroscience 9 (2016) 1-16.

[33] G. Zhang, T.A. Neubert, B.A. Jordan, RNA Binding Proteins Accumulate at the Postsynaptic Density with Synaptic Activity, Journal of Neuroscience 32 (2012) 599609.

[34] Y. Kanai, N. Dohmae, N. Hirokawa, Kinesin transports RNA: Isolation and characterization of an RNA-transporting granule, Neuron 43 (2004) 513-525.

[35] A. Yoshimura, R. Fujii, Y. Watanabe, S. Okabe, K. Fukui, T. Takumi, Myosin-Va facilitates the accumulation of mRNA/protein complex in dendritic spines, Curr Biol 16(23) (2006) 2345-51. 
[36] R. Fujii, T. Takumi, TLS facilitates transport of mRNA encoding an actinstabilizing protein to dendritic spines., Journal of cell science 118 (2005) 5755-5765. [37] R. Groppo, J.D. Richter, Translational control from head to tail, Curr Opin Cell Biol 21(3) (2009) 444-51.

[38] J.C. Darnell, E. Klann, The translation of translational control by FMRP: therapeutic targets for FXS, Nat Neurosci 16(11) (2013) 1530-6.

[39] S.H. Kim, N.P. Shanware, M.J. Bowler, R.S. Tibbetts, Amyotrophic lateral sclerosis-associated proteins TDP-43 and FUS/TLS function in a common biochemical complex to co-regulate HDAC6 mRNA, J Biol Chem 285(44) (2010) 34097-105.

[40] A.N. Coyne, S.B. Yamada, B.B. Siddegowda, P.S. Estes, B.L. Zaepfel, J.S. Johannesmeyer, D.B. Lockwood, L.T. Pham, M.P. Hart, J.A. Cassel, B. Freibaum, A.V. Boehringer, J. Paul Taylor, A.B. Reitz, A.D. Gitler, D.C. Zarnescu, Fragile X protein mitigates TDP-43 toxicity by remodeling RNA granules and restoring translation, Human Molecular Genetics 24 (2015) 6886-6898.

[41] A. Russo, R. Scardigli, F.L. Regina, M.E. Murray, N. Romano, D.W. Dickson, B. Wolozin, A. Cattaneo, M. Ceci, Increased cytoplasmic TDP-43 reduces global protein synthesis by interacting with Rack1 on polyribosomes, Human Molecular Genetics 26 (2017) 1407-1418.

[42] P. Majumder, J.F. Chu, B. Chatterjee, K.B.S. Swamy, C.K.J. Shen, Co-regulation of mRNA translation by TDP-43 and Fragile X Syndrome protein FMRP, Acta Neuropathologica 132 (2016) 1-18.

[43] P. Majumder, Y.T. Chen, J.K. Bose, C.C. Wu, W.C. Cheng, S.J. Cheng, Y.H. Fang, Y.L. Chen, K.J. Tsai, C.C. Lien, C.K.J. Shen, TDP-43 regulates the mammalian spinogenesis through translational repression of Rac1, Acta Neuropathologica 124 (2012) 231-245.

[44] N. Neelagandan, G. Gonnella, S. Dang, P.C. Janiesch, K.K. Miller, K. Küchler, R.F. Marques, D. Indenbirken, M. Alawi, A. Grundhoff, S. Kurtz, K.E. Duncan, TDP-43 enhances translation of specific mRNAs linked to neurodegenerative disease, Nucleic Acids Research 47 (2018) 341-361.

[45] L. Macnair, S. Xiao, D. Miletic, M. Ghani, J.P. Julien, J. Keith, L. Zinman, E. Rogaeva, J. Robertson, MTHFSD and DDX58 are novel RNA-binding proteins abnormally regulated in amyotrophic lateral sclerosis, Brain 139 (2016) 86-100. 
[46] J. Lopez-Erauskin, T. Tadokoro, M.W. Baughn, B. Myers, M. McAlonis-Downes, C. Chillon-Marinas, J.N. Asiaban, J. Artates, A.T. Bui, A.P. Vetto, S.K. Lee, A.V. Le, Y. Sun, M. Jambeau, J. Boubaker, D. Swing, J. Qiu, G.G. Hicks, Z. Ouyang, X.D. Fu, L. Tessarollo, S.C. Ling, P.A. Parone, C.E. Shaw, M. Marsala, C. Lagier-Tourenne, D.W. Cleveland, S. Da Cruz, ALS/FTD-Linked Mutation in FUS Suppresses Intra-axonal Protein Synthesis and Drives Disease Without Nuclear Loss-of-Function of FUS, Neuron 100(4) (2018) 816-830 e7.

[47] T. Murakami, S. Qamar, J.Q. Lin, G.S.K. Schierle, E. Rees, A. Miyashita, A.R. Costa, R.B. Dodd, F.T.S. Chan, C.H. Michel, D. Kronenberg-Versteeg, Y. Li, S.P. Yang, Y. Wakutani, W. Meadows, R.R. Ferry, L. Dong, G.G. Tartaglia, G. Favrin, W.L. Lin, D.W. Dickson, M. Zhen, D. Ron, G. Schmitt-Ulms, P.E. Fraser, N.A. Shneider, C. Holt, M. Vendruscolo, C.F. Kaminski, P. St George-Hyslop, ALS/FTD Mutation-Induced Phase Transition of FUS Liquid Droplets and Reversible Hydrogels into Irreversible Hydrogels Impairs RNP Granule Function, Neuron 88 (2015) 678-690. [48] K. Yasuda, H. Zhang, D. Loiselle, T. Haystead, I.G. Macara, S. Mili, The RNAbinding protein Fus directs translation of localized mrnas in APC-RNP granules, Journal of Cell Biology 203 (2013) 737-746.

[49] T. Zhang, Y.C. Wu, P. Mullane, Y.J. Ji, H. Liu, L. He, A. Arora, H.Y. Hwang, A.F. Alessi, A.G. Niaki, G. Periz, L. Guo, H. Wang, E. Elkayam, L. Joshua-Tor, S. Myong, J.K. Kim, J. Shorter, S.E. Ong, A.K.L. Leung, J. Wang, FUS Regulates Activity of MicroRNAMediated Gene Silencing, Mol Cell 69(5) (2018) 787-801 e8.

[50] A. Emde, C. Eitan, L.L. Liou, R.T. Libby, N. Rivkin, I. Magen, I. Reichenstein, H. Oppenheim, R. Eilam, A. Silvestroni, B. Alajajian, I.Z. Ben-Dov, J. Aebischer, A. Savidor, Y. Levin, R. Sons, S.M. Hammond, J.M. Ravits, T. Moller, E. Hornstein, Dysregulated miRNA biogenesis downstream of cellular stress and ALS-causing mutations: a new mechanism for ALS, EMBO J 34(21) (2015) 2633-51. [51] P. Rinchetti, M. Rizzuti, I. Faravelli, S. Corti, MicroRNA Metabolism and Dysregulation in Amyotrophic Lateral Sclerosis, Mol Neurobiol 55(3) (2018) 26172630.

[52] S. Haramati, E. Chapnik, Y. Sztainberg, R. Eilam, R. Zwang, N. Gershoni, E. McGlinn, P.W. Heiser, A.M. Wills, I. Wirguin, L.L. Rubin, H. Misawa, C.J. Tabin, R. 
Brown, Jr., A. Chen, E. Hornstein, miRNA malfunction causes spinal motor neuron disease, Proc Natl Acad Sci U S A 107(29) (2010) 13111-6.

[53] Y. Kawahara, A. Mieda-Sato, TDP-43 promotes microRNA biogenesis as a component of the Drosha and Dicer complexes, Proc Natl Acad Sci U S A 109(9) (2012) 3347-52.

[54] E. Buratti, L. De Conti, C. Stuani, M. Romano, M. Baralle, F. Baralle, Nuclear factor TDP-43 can affect selected microRNA levels, FEBS J 277(10) (2010) 2268-81. [55] V. Di Carlo, E. Grossi, P. Laneve, M. Morlando, S. Dini Modigliani, M. Ballarino, I. Bozzoni, E. Caffarelli, TDP-43 regulates the microprocessor complex activity during in vitro neuronal differentiation, Mol Neurobiol 48(3) (2013) 952-63.

[56] M. Morlando, S. Dini Modigliani, G. Torrelli, A. Rosa, V. Di Carlo, E. Caffarelli, I. Bozzoni, FUS stimulates microRNA biogenesis by facilitating co-transcriptional Drosha recruitment, EMBO J 31(24) (2012) 4502-10.

[57] S. Sambandan, G. Akbalik, L. Kochen, J. Rinne, J. Kahlstatt, C. Glock, G. Tushev, B. Alvarez-Castelao, A. Heckel, E.M. Schuman, Activity-dependent spatially localized miRNA maturation in neuronal dendrites, Science 355(6325) (2017) 634-637. [58] P. Anderson, N. Kedersha, Stress granules: the Tao of RNA triage, Trends Biochem Sci 33(3) (2008) 141-50.

[59] D.S.W. Protter, R. Parker, Principles and Properties of Stress Granules, Trends Cell Biol 26(9) (2016) 668-679.

[60] S. Souquere, S. Mollet, M. Kress, F. Dautry, G. Pierron, D. Weil, Unravelling the ultrastructure of stress granules and associated P-bodies in human cells, J Cell Sci 122(Pt 20) (2009) 3619-26.

[61] Y. Khalfallah, R. Kuta, C. Grasmuck, A. Prat, H.D. Durham, C. Vande Velde, TDP43 regulation of stress granule dynamics in neurodegenerative disease-relevant cell types, Sci Rep 8(1) (2018) 7551.

[62] I.R. Mackenzie, A.M. Nicholson, M. Sarkar, J. Messing, M.D. Purice, C. Pottier, K. Annu, M. Baker, R.B. Perkerson, A. Kurti, B.J. Matchett, T. Mittag, J. Temirov, G.R. Hsiung, C. Krieger, M.E. Murray, M. Kato, J.D. Fryer, L. Petrucelli, L. Zinman, S. Weintraub, M. Mesulam, J. Keith, S.A. Zivkovic, V. Hirsch-Reinshagen, R.P. Roos, S. Zuchner, N.R. Graff-Radford, R.C. Petersen, R.J. Caselli, Z.K. Wszolek, E. Finger, C. Lippa, D. Lacomis, H. Stewart, D.W. Dickson, H.J. Kim, E. Rogaeva, E. Bigio, K.B. 
Boylan, J.P. Taylor, R. Rademakers, TIA1 Mutations in Amyotrophic Lateral Sclerosis and Frontotemporal Dementia Promote Phase Separation and Alter Stress Granule Dynamics, Neuron 95(4) (2017) 808-816.e9.

[63] A. Molliex, J. Temirov, J. Lee, M. Coughlin, A.P. Kanagaraj, H.J. Kim, T. Mittag, J.P. Taylor, Phase separation by low complexity domains promotes stress granule assembly and drives pathological fibrillization, Cell 163(1) (2015) 123-33.

[64] A.E. Conicella, G.H. Zerze, J. Mittal, N.L. Fawzi, ALS Mutations Disrupt Phase Separation Mediated by alpha-Helical Structure in the TDP-43 Low-Complexity CTerminal Domain, Structure 24(9) (2016) 1537-49.

[65] A. Patel, H.O. Lee, L. Jawerth, S. Maharana, M. Jahnel, M.Y. Hein, S. Stoynov, J. Mahamid, S. Saha, T.M. Franzmann, A. Pozniakovski, I. Poser, N. Maghelli, L.A. Royer, M. Weigert, E.W. Myers, S. Grill, D. Drechsel, A.A. Hyman, S. Alberti, A Liquid-to-Solid Phase Transition of the ALS Protein FUS Accelerated by Disease Mutation, Cell 162(5) (2015) 1066-77.

[66] S. Jain, J.R. Wheeler, R.W. Walters, A. Agrawal, A. Barsic, R. Parker, ATPaseModulated Stress Granules Contain a Diverse Proteome and Substructure, Cell 164(3) (2016) 487-98.

[67] S. Markmiller, S. Soltanieh, K.L. Server, R. Mak, W. Jin, M.Y. Fang, E.C. Luo, F. Krach, D. Yang, A. Sen, A. Fulzele, J.M. Wozniak, D.J. Gonzalez, M.W. Kankel, F.B. Gao, E.J. Bennett, E. Lecuyer, G.W. Yeo, Context-Dependent and Disease-Specific Diversity in Protein Interactions within Stress Granules, Cell 172(3) (2018) 590604.e13.

[68] C. Colombrita, E. Zennaro, C. Fallini, M. Weber, A. Sommacal, E. Buratti, V. Silani, A. Ratti, TDP-43 is recruited to stress granules in conditions of oxidative insult, J Neurochem 111(4) (2009) 1051-61.

[69] M.K. Andersson, A. Stahlberg, Y. Arvidsson, A. Olofsson, H. Semb, G. Stenman, O. Nilsson, P. Aman, The multifunctional FUS, EWS and TAF15 proto-oncoproteins show cell type-specific expression patterns and involvement in cell spreading and stress response, BMC Cell Biol 9 (2008) 37.

[70] R.R. Sama, C.L. Ward, L.J. Kaushansky, N. Lemay, S. Ishigaki, F. Urano, D.A. Bosco, FUS/TLS assembles into stress granules and is a prosurvival factor during hyperosmolar stress, J Cell Physiol 228(11) (2013) 2222-31. 
[71] D.A. Bosco, N. Lemay, H.K. Ko, H. Zhou, C. Burke, T.J. Kwiatkowski, Jr., P. Sapp, D. McKenna-Yasek, R.H. Brown, Jr., L.J. Hayward, Mutant FUS proteins that cause amyotrophic lateral sclerosis incorporate into stress granules, Hum Mol Genet 19(21) (2010) 4160-75.

[72] A. Devoy, B. Kalmar, M. Stewart, H. Park, B. Burke, S.J. Noy, Y. Redhead, J. Humphrey, K. Lo, J. Jaeger, A. Mejia Maza, P. Sivakumar, C. Bertolin, G. Soraru, V. Plagnol, L. Greensmith, A. Acevedo Arozena, A.M. Isaacs, B. Davies, P. Fratta, E.M.C. Fisher, Humanized mutant FUS drives progressive motor neuron degeneration without aggregation in 'FUSDelta14' knockin mice, Brain 140(11) (2017) 2797-2805. [73] M. Lo Bello, F. Di Fini, A. Notaro, R. Spataro, F.L. Conforti, V. La Bella, ALSRelated Mutant FUS Protein Is Mislocalized to Cytoplasm and Is Recruited into Stress Granules of Fibroblasts from Asymptomatic FUS P525L Mutation Carriers, Neurodegener Dis 17(6) (2017) 292-303.

[74] J. Lenzi, R. De Santis, V. de Turris, M. Morlando, P. Laneve, A. Calvo, V. Caliendo, A. Chio, A. Rosa, I. Bozzoni, ALS mutant FUS proteins are recruited into stress granules in induced pluripotent stem cell-derived motoneurons, Dis Model Mech 8(7) (2015) 755-66.

[75] D. Dormann, R. Rodde, D. Edbauer, E. Bentmann, I. Fischer, A. Hruscha, M.E. Than, I.R. Mackenzie, A. Capell, B. Schmid, M. Neumann, C. Haass, ALS-associated fused in sarcoma (FUS) mutations disrupt Transportin-mediated nuclear import, EMBO J 29(16) (2010) 2841-57.

[76] M. Hofweber, S. Hutten, B. Bourgeois, E. Spreitzer, A. Niedner-Boblenz, M. Schifferer, M.D. Ruepp, M. Simons, D. Niessing, T. Madl, D. Dormann, Phase Separation of FUS Is Suppressed by Its Nuclear Import Receptor and Arginine Methylation, Cell 173(3) (2018) 706-719.e13.

[77] L. Guo, H.J. Kim, H. Wang, J. Monaghan, F. Freyermuth, J.C. Sung, K. O'Donovan, C.M. Fare, Z. Diaz, N. Singh, Z.C. Zhang, M. Coughlin, E.A. Sweeny, M.E. DeSantis, M.E. Jackrel, C.B. Rodell, J.A. Burdick, O.D. King, A.D. Gitler, C. Lagier-Tourenne, U.B. Pandey, Y.M. Chook, J.P. Taylor, J. Shorter, Nuclear-Import Receptors Reverse Aberrant Phase Transitions of RNA-Binding Proteins with Prion-like Domains, Cell 173(3) (2018) 677-692.e20. 
[78] K.K. McDonald, A. Aulas, L. Destroismaisons, S. Pickles, E. Beleac, W. Camu, G.A. Rouleau, C. Vande Velde, TAR DNA-binding protein 43 (TDP-43) regulates stress granule dynamics via differential regulation of G3BP and TIA-1, Hum Mol Genet 20(7) (2011) 1400-10.

[79] A. Aulas, S. Stabile, C. Vande Velde, Endogenous TDP-43, but not FUS, contributes to stress granule assembly via G3BP, Mol Neurodegener 7 (2012) 54. [80] C.M. Dewey, B. Cenik, C.F. Sephton, D.R. Dries, P. Mayer, 3rd, S.K. Good, B.A. Johnson, J. Herz, G. Yu, TDP-43 is directed to stress granules by sorbitol, a novel physiological osmotic and oxidative stressor, Mol Cell Biol 31(5) (2011) 1098-108. [81] D.M. Baron, L.J. Kaushansky, C.L. Ward, R.R. Sama, R.J. Chian, K.J. Boggio, A.J. Quaresma, J.A. Nickerson, D.A. Bosco, Amyotrophic lateral sclerosis-linked FUS/TLS alters stress granule assembly and dynamics, Mol Neurodegener 8 (2013) 30.

[82] S. Orru, P. Coni, A. Floris, R. Littera, C. Carcassi, V. Sogos, C. Brancia, Reduced stress granule formation and cell death in fibroblasts with the A382T mutation of TARDBP gene: evidence for loss of TDP-43 nuclear function, Hum Mol Genet 25(20) (2016) 4473-4483.

[83] J.R. Acosta, C. Goldsbury, C. Winnick, A.P. Badrock, S.T. Fraser, A.S. Laird, T.E. Hall, E.K. Don, J.A. Fifita, I.P. Blair, G.A. Nicholson, N.J. Cole, Mutant human FUS Is ubiquitously mislocalized and generates persistent stress granules in primary cultured transgenic zebrafish cells, PLoS One 9(6) (2014) e90572.

[84] G. Antonacci, V. de Turris, A. Rosa, G. Ruocco, Background-deflection Brillouin microscopy reveals altered biomechanics of intracellular stress granules by ALS protein FUS, Commun Biol 1 (2018) 139.

[85] K. Volkening, C. Leystra-Lantz, W. Yang, H. Jaffee, M.J. Strong, Tar DNA binding protein of $43 \mathrm{kDa}$ (TDP-43), 14-3-3 proteins and copper/zinc superoxide dismutase (SOD1) interact to modulate NFL mRNA stability. Implications for altered RNA processing in amyotrophic lateral sclerosis (ALS), Brain Res 1305 (2009) 168-82. [86] L. Liu-Yesucevitz, A. Bilgutay, Y.J. Zhang, T. Vanderweyde, A. Citro, T. Mehta, N. Zaarur, A. McKee, R. Bowser, M. Sherman, L. Petrucelli, B. Wolozin, Tar DNA binding protein-43 (TDP-43) associates with stress granules: analysis of cultured cells and pathological brain tissue, PLoS One 5(10) (2010) e13250. 
[87] Y.R. Li, O.D. King, J. Shorter, A.D. Gitler, Stress granules as crucibles of ALS pathogenesis, J Cell Biol 201(3) (2013) 361-72.

[88] S.J. Parker, J. Meyerowitz, J.L. James, J.R. Liddell, P.J. Crouch, K.M. Kanninen, A.R. White, Endogenous TDP-43 localized to stress granules can subsequently form protein aggregates, Neurochem Int 60(4) (2012) 415-24.

[89] P. Zhang, B. Fan, P. Yang, J. Temirov, J. Messing, H.J. Kim, J.P. Taylor,

OptoGranules reveal the evolution of stress granules to ALS-FTD pathology, bioRxiv (2018) 348870.

[90] F. Gasset-Rosa, S. Lu, H. Yu, C. Chen, Z. Melamed, L. Guo, J. Shorter, S. Da Cruz, D.W. Cleveland, Cytoplasmic TDP-43 De-mixing Independent of Stress Granules Drives Inhibition of Nuclear Import, Loss of Nuclear TDP-43, and Cell Death, Neuron 102(2) (2019) 339-357 e7.

[91] T.O. Vogler, J.R. Wheeler, E.D. Nguyen, M.P. Hughes, K.A. Britson, E. Lester, B. Rao, N.D. Betta, O.N. Whitney, T.E. Ewachiw, E. Gomes, J. Shorter, T.E. Lloyd, D.S. Eisenberg, J.P. Taylor, A.M. Johnson, B.B. Olwin, R. Parker, TDP-43 and RNA form amyloid-like myo-granules in regenerating muscle, Nature 563(7732) (2018) 508513.

[92] S. Maharana, J. Wang, D.K. Papadopoulos, D. Richter, A. Pozniakovsky, I. Poser, M. Bickle, S. Rizk, J. Guillen-Boixet, T.M. Franzmann, M. Jahnel, L. Marrone, Y.T. Chang, J. Sterneckert, P. Tomancak, A.A. Hyman, S. Alberti, RNA buffers the phase separation behavior of prion-like RNA binding proteins, Science 360(6391) (2018) 918-921.

[93] J.R. Mann, A.M. Gleixner, J.C. Mauna, E. Gomes, M.R. DeChellis-Marks, P.G. Needham, K.E. Copley, B. Hurtle, B. Portz, N.J. Pyles, L. Guo, C.B. Calder, Z.P. Wills, U.B. Pandey, J.K. Kofler, J.L. Brodsky, A. Thathiah, J. Shorter, C.J. Donnelly, RNA Binding Antagonizes Neurotoxic Phase Transitions of TDP-43, Neuron 102(2) (2019) 321-338 e8.

[94] W. Wang, L. Wang, J. Lu, S.L. Siedlak, H. Fujioka, J. Liang, S. Jiang, X. Ma, Z. Jiang, E.L. da Rocha, M. Sheng, H. Choi, P.H. Lerou, H. Li, X. Wang, The inhibition of TDP-43 mitochondrial localization blocks its neuronal toxicity., Nature medicine 22 (2016) 869-78. 
[95] J. Deng, P. Wang, X. Chen, H. Cheng, J. Liu, K. Fushimi, L. Zhu, J.Y. Wu, FUS interacts with ATP synthase beta subunit and induces mitochondrial unfolded protein response in cellular and animal models, Proceedings of the National Academy of Sciences (2018) 201806655.

[96] K. Izumikawa, Y. Nobe, H. Yoshikawa, H. Ishikawa, Y. Miura, H. Nakayama, T. Nonaka, M. Hasegawa, N. Egawa, H. Inoue, K. Nishikawa, K. Yamano, R.J. Simpson, M. Taoka, Y. Yamauchi, T. Isobe, N. Takahashi, TDP-43 stabilises the processing intermediates of mitochondrial transcripts, Scientific Reports 7 (2017) 1-14. [97] H. Kawamata, P. Peixoto, C. Konrad, G. Palomo, K. Bredvik, M. Gerges, F. Valsecchi, L. Petrucelli, J.M. Ravits, A. Starkov, G. Manfredi, Mutant TDP-43 does not impair mitochondrial bioenergetics in vitro and in vivo, Molecular Neurodegeneration 12 (2017) 1-15.

[98] J. Deng, M. Yang, Y. Chen, X. Chen, J. Liu, S. Sun, H. Cheng, Y. Li, E.H. Bigio, M. Mesulam, Q. Xu, S. Du, K. Fushimi, L. Zhu, J.Y. Wu, FUS Interacts with HSP60 to Promote Mitochondrial Damage, PLoS Genetics 11 (2015) 1-30.

[99] T. Nakaya, M. Maragkakis, Amyotrophic Lateral Sclerosis associated FUS mutation shortens mitochondria and induces neurotoxicity, Scientific Reports 8 (2018) 15575.

[100] S.A. Davis, S. Itaman, C.M. Khalid-Janney, J.A. Sherard, J.A. Dowell, N.J. Cairns, M.A. Gitcho, TDP-43 interacts with mitochondrial proteins critical for mitophagy and mitochondrial dynamics, Neuroscience Letters 678 (2018) 8-15.

[101] R. Stoica, K.J. De Vos, S. Paillusson, S. Mueller, R.M. Sancho, K.F. Lau, G. VizcayBarrena, W.L. Lin, Y.F. Xu, J. Lewis, D.W. Dickson, L. Petrucelli, J.C. Mitchell, C.E. Shaw, C.C.J. Miller, ER-mitochondria associations are regulated by the VAPB-PTPIP51 interaction and are disrupted by ALS/FTD-associated TDP-43, Nature Communications 5 (2014).

[102] R. Stoica, S. Paillusson, P. Gomez-suaga, J.C. Mitchell, D.H.W. Lau, E.H. Gray, R.M. Sancho, G. Vizcay-barrena, K.J.D. Vos, C.E. Shaw, D.P. Hanger, W. Noble, C.C.J. Miller, ALS / FTD-associated FUS activates GSK- 3 b to disrupt the VAPB - PTPIP 51 interaction and ER - mitochondria associations, EMBO Rep (2016) 1-17. [103] N. Ramesh, U.B. Pandey, Autophagy Dysregulation in ALS: When Protein Aggregates Get Out of Hand, Front Mol Neurosci 10 (2017) 263. 
[104] J.K. Bose, C.C. Huang, C.K. Shen, Regulation of autophagy by neuropathological protein TDP-43, J Biol Chem 286(52) (2011) 44441-8.

[105] P. Torres, O. Ramirez-Nunez, R. Romero-Guevara, G. Bares, A.B. GranadoSerrano, V. Ayala, J. Boada, L. Fontdevila, M. Povedano, D. Sanchis, R. Pamplona, I. Ferrer, M. Portero-Otin, Cryptic exon splicing function of TARDBP interacts with autophagy in nervous tissue, Autophagy 14(8) (2018) 1398-1403.

[106] Q. Xia, H. Wang, Z. Hao, C. Fu, Q. Hu, F. Gao, H. Ren, D. Chen, J. Han, Z. Ying, G. Wang, TDP-43 loss of function increases TFEB activity and blocks autophagosomelysosome fusion, Embo j 35(2) (2016) 121-42.

[107] X. Wang, S. Zhou, X. Ding, M. Ma, J. Zhang, Y. Zhou, E. Wu, J. Teng, Activation of ER Stress and Autophagy Induced by TDP-43 A315T as Pathogenic Mechanism and the Corresponding Histological Changes in Skin as Potential Biomarker for ALS with the Mutation, Int J Biol Sci 11(10) (2015) 1140-9.

[108] K.Y. Soo, J. Sultana, A.E. King, R. Atkinson, S.T. Warraich, V. Sundaramoorthy, I. Blair, M.A. Farg, J.D. Atkin, ALS-associated mutant FUS inhibits macroautophagy which is restored by overexpression of Rab1, Cell Death Discov 1 (2015) 15030. [109] H.H. Ryu, M.H. Jun, K.J. Min, D.J. Jang, Y.S. Lee, H.K. Kim, J.A. Lee, Autophagy regulates amyotrophic lateral sclerosis-linked fused in sarcoma-positive stress granules in neurons, Neurobiol Aging 35(12) (2014) 2822-2831.

[110] C.E. Holt, E.M. Schuman, The central dogma decentralized: new perspectives on RNA function and local translation in neurons, Neuron 80(3) (2013) 648-57. [111] T. Shigeoka, H. Jung, J. Jung, B. Turner-Bridger, J. Ohk, J.Q. Lin, P.S. Amieux, C.E. Holt, Dynamic Axonal Translation in Developing and Mature Visual Circuits, Cell 166(1) (2016) 181-92.

[112] M. Polymenidou, C. Lagier-Tourenne, K.R. Hutt, S.C. Huelga, J. Moran, T.Y. Liang, S.C. Ling, E. Sun, E. Wancewicz, C. Mazur, H. Kordasiewicz, Y. Sedaghat, J.P. Donohue, L. Shiue, C.F. Bennett, G.W. Yeo, D.W. Cleveland, Long pre-mRNA depletion and RNA missplicing contribute to neuronal vulnerability from loss of TDP43, Nature Neuroscience 14 (2011) 459-468.

[113] C.F. Sephton, C. Cenik, A. Kucukural, E.B. Dammer, B. Cenik, Y. Han, C.M. Dewey, F.P. Roth, J. Herz, J. Peng, M.J. Moore, G. Yu, Identification of neuronal RNA 
targets of TDP-43-containing ribonucleoprotein complexes, Journal of Biological Chemistry 286 (2011) 1204-1215.

[114] C. Lagier-Tourenne, M. Polymenidou, K.R. Hutt, A.Q. Vu, M. Baughn, S.C. Huelga, K.M. Clutario, S.C. Ling, T.Y. Liang, C. Mazur, E. Wancewicz, A.S. Kim, A. Watt, S. Freier, G.G. Hicks, J.P. Donohue, L. Shiue, C.F. Bennett, J. Ravits, D.W. Cleveland, G.W. Yeo, Divergent roles of ALS-linked proteins FUS/TLS and TDP-43 intersect in processing long pre-mRNAs, Nat Neurosci 15(11) (2012) 1488-97.

[115] J.J. Herzog, M. Deshpande, L. Shapiro, A.A. Rodal, S. Paradis, TDP-43 misexpression causes defects in dendritic growth, Scientific Reports 7 (2017) 1-13. [116] J.H. Han, T.H. Yu, H.H. Ryu, M.H. Jun, B.K. Ban, D.J. Jang, J.A. Lee, ALS/FTLDlinked TDP-43 regulates neurite morphology and cell survival in differentiated neurons, Experimental Cell Research 319 (2013) 1998-2005.

[117] C.F. Sephton, a.a. Tang, a. Kulkarni, J. West, M. Brooks, J.J. Stubblefield, Y. Liu, M.Q. Zhang, C.B. Green, K.M. Huber, E.J. Huang, J. Herz, G. Yu, Activity-dependent FUS dysregulation disrupts synaptic homeostasis, Proceedings of the National Academy of Sciences 111 (2014) E4769-E4778.

[118] J.B. Machamer, B.M. Woolums, G.G. Fuller, T.E. Lloyd, FUS causes synaptic hyperexcitability in Drosophila dendritic arborization neurons, Brain Res 1693(Pt A) (2018) 55-66.

[119] C. Huang, J. Tong, F. Bi, Q. Wu, B. Huang, H. Zhou, X.G. Xia, Entorhinal cortical neurons are the primary targets of FUS mislocalization and ubiquitin aggregation in FUS transgenic rats, Human Molecular Genetics 21 (2012) 4602-4614.

[120] L. Liu-Yesucevitz, G.J. Bassell, a.D. Gitler, a.C. Hart, E. Klann, J.D. Richter, S.T. Warren, B. Wolozin, Local RNA Translation at the Synapse and in Disease, Journal of Neuroscience 31 (2011) 16086-16093.

[121] A.N. Coyne, B.B. Siddegowda, P.S. Estes, J. Johannesmeyer, T. Kovalik, S.G. Daniel, A. Pearson, R. Bowser, D.C. Zarnescu, Futsch/MAP1B mRNA Is a Translational Target of TDP-43 and Is Neuroprotective in a Drosophila Model of Amyotrophic Lateral Sclerosis, Journal of Neuroscience 34 (2014) 15962-15974. [122] V.K. Godena, G. Romano, M. Romano, C. Appocher, R. Klima, E. Buratti, F.E. Baralle, F. Feiguin, TDP-43 regulates drosophila neuromuscular junctions growth by 
modulating futsch/MAP1B levels and synaptic microtubules organization, PLoS ONE 6 (2011).

[123] A.N. Coyne, I. Lorenzini, C.C. Chou, M. Torvund, R.S. Rogers, A. Starr, B.L. Zaepfel, J. Levy, J. Johannesmeyer, J.C. Schwartz, H. Nishimune, K. Zinsmaier, W. Rossoll, R. Sattler, D.C. Zarnescu, Post-transcriptional Inhibition of Hsc70-4/HSPA8 Expression Leads to Synaptic Vesicle Cycling Defects in Multiple Models of ALS, Cell Reports 21 (2017) 110-125.

[124] H. Husi, M.a. Ward, J.S. Choudhary, W.P. Blackstock, S.G. Grant, Proteomic analysis of NMDA receptor-adhesion protein signaling complexes., Nature neuroscience 3 (2000) 661-669.

[125] N. Aoki, S. Higashi, I. Kawakami, Z. Kobayashi, M. Hosokawa, O. Katsuse, T. Togo, Y. Hirayasu, H. Akiyama, Localization of fused in sarcoma (FUS) protein to the post-synaptic density in the brain, Acta Neuropathologica 124 (2012) 383-394. [126] J.B. Machamer, S.E. Collins, T.E. Lloyd, The ALS gene FUS regulates synaptic transmission at the Drosophila neuromuscular junction, Hum Mol Genet 23(14) (2014) 3810-22.

[127] T. Murakami, S. Qamar, J.Q. Lin, G.S. Schierle, E. Rees, A. Miyashita, A.R. Costa, R.B. Dodd, F.T. Chan, C.H. Michel, D. Kronenberg-Versteeg, Y. Li, S.P. Yang, Y. Wakutani, W. Meadows, R.R. Ferry, L. Dong, G.G. Tartaglia, G. Favrin, W.L. Lin, D.W. Dickson, M. Zhen, D. Ron, G. Schmitt-Ulms, P.E. Fraser, N.A. Shneider, C. Holt, M. Vendruscolo, C.F. Kaminski, P. St George-Hyslop, ALS/FTD Mutation-Induced Phase Transition of FUS Liquid Droplets and Reversible Hydrogels into Irreversible Hydrogels Impairs RNP Granule Function, Neuron 88(4) (2015) 678-90. [128] E.J. Groen, K. Fumoto, A.M. Blokhuis, J. Engelen-Lee, Y. Zhou, D.M. van den Heuvel, M. Koppers, F. van Diggelen, J. van Heest, J.A. Demmers, J. Kirby, P.J. Shaw, E. Aronica, W.G. Spliet, J.H. Veldink, L.H. van den Berg, R.J. Pasterkamp, ALSassociated mutations in FUS disrupt the axonal distribution and function of SMN, Hum Mol Genet 22(18) (2013) 3690-704.

[129] Y. Iguchi, M. Katsuno, J. Niwa, S. Takagi, S. Ishigaki, K. Ikenaka, K. Kawai, H. Watanabe, K. Yamanaka, R. Takahashi, H. Misawa, S. Sasaki, F. Tanaka, G. Sobue, Loss of TDP-43 causes age-dependent progressive motor neuron degeneration, Brain 136(Pt 5) (2013) 1371-82. 
[130] L.S. Wu, W.C. Cheng, C.K. Shen, Targeted depletion of TDP-43 expression in the spinal cord motor neurons leads to the development of amyotrophic lateral sclerosis-like phenotypes in mice, J Biol Chem 287(33) (2012) 27335-44.

[131] Y. Kino, C. Washizu, M. Kurosawa, M. Yamada, H. Miyazaki, T. Akagi, T. Hashikawa, H. Doi, T. Takumi, G.G. Hicks, N. Hattori, T. Shimogori, N. Nukina, FUS/TLS deficiency causes behavioral and pathological abnormalities distinct from amyotrophic lateral sclerosis, Acta Neuropathol Commun 3 (2015) 24. 


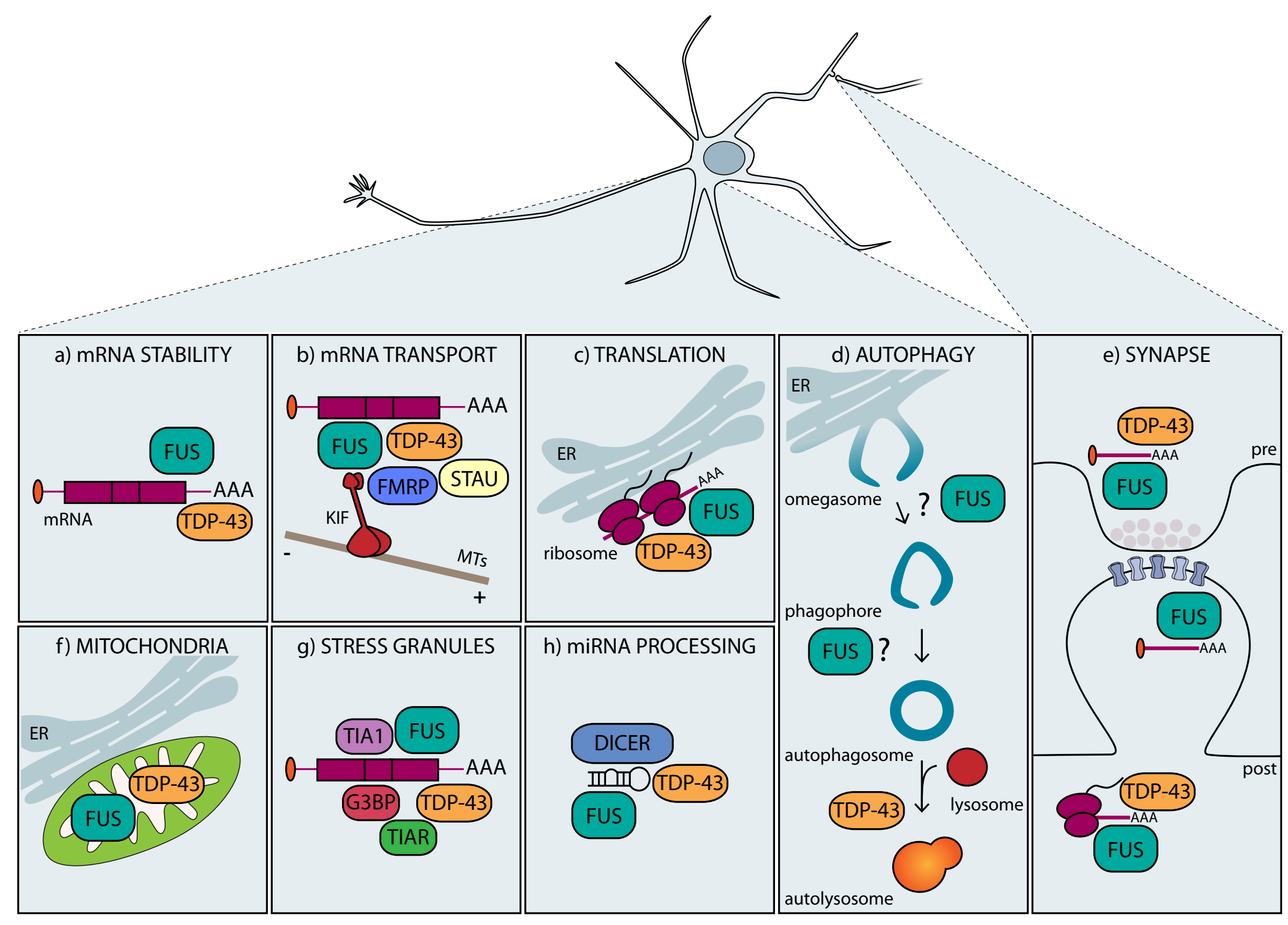




\section{Figure 1. Cytoplasmic roles of TDP-43 and FUS.}

In the cytoplasm TDP-43 and FUS are involved in many processes. They regulate mRNA stability (a); together with other RBPs, such as Staufen and FMRP, they can be part of RNA granules that are transported along the microtubules (MTs) by molecular motors (b). TDP-43 and FUS are involved in the regulation of translation (c). Both RBPs can regulate autophagy. FUS has been proposed to interfere with the formation of omegasomes and/or autophagosomes, while TDP43 regulates key factors involved in the fusion of autophagosomes with lysosomes (d). TDP-43 and FUS are present at the pre- and post-synapse, regulating mRNA localisation and translation (e). They localise to mitochondria, where they can regulate the expression of mitochondrial transcripts, and, through GSK3beta, they can alter ER-mitochondria contact sites (f). TDP-43 and FUS are involved in stress granule dynamics ( $\mathrm{g}$ ) and the cytoplasmic processing of miRNAs by DICER $(h)$. 